\title{
Reduction of product development time by team formation method in lean manufacturing
}

\author{
T. Venkatamuni ${ }^{1}$ and A. Ramakrishna Rao ${ }^{2}$ \\ ${ }^{1}$ Mechanial Engineering, Sathyabama University, Chennai-600119, India \\ ${ }^{2}$ Department of Mechanical Engineering, S.V.U.C.E., S.V.University, Tirupathi -2, India \\ tvmuni123@gmail.com
}

\begin{abstract}
This paper deals with team formation role in product design and development for lean manufacturing. Its implementation offers the potential for faster product development with fewer engineering hours, improved manufacturability of products, higher quality products fewer start up problems and faster time to market. The concept of multi-functional teams is one of the key aspects of problem solving related to product design in many industries. The membership of a team depends on the type of product to be developed, number of customer requirements, engineering or product characteristics, and so on. The analytic hierarchy process (AHP) tool is used to find the individual specialist weights over product design. In this paper the group of people available in each discipline is mentioned at lower level. The mathematical model is developed for deciding the team members in product design with constraints of number of projects, time and budget.
\end{abstract}

Keywords: AHP, Lean manufacturing, multi functional teams, product design.

\section{Introduction}

Analytic hierarchical process (AHP) is a technique which enables decision makers to build a model to take hierarchical decisions structurally (Aczel \& Saaty 1983). For the fast product development, this decision making process is very much essential. Nowadays, the concept of multi-functional teams is one of the key aspects of problem solving related to product design in many industries (Arbel \& Seidmann, 1994). Specialists from various disciplines like design, manufacturing, quality testing, and marketing departments form a group and take decision in new product development collectively (Mullens, 1994). AHP process provides a structured framework for setting priorities on each level of the hierarchy, using pair wise comparisons, a process of comparing each pair of decision factors at a given level of the model for their relative importance with respect to their parent level. The mathematical programming model is developed to determine optimal composition of a team (Lida XU et.al., 2007). The objective of the problem is structured, unified, and capable of dealing with the tangible and intangible aspects of forming multi-functional teams (Askin \& Sodhi, 1994). The AHP methodology captures the importance of various elements of the problem, suggesting the course of action. Also, the user acceptability, and confidence in the data provided by the AHP methodology is high compared with other multiattribute-decision approaches. The method developed by Saaty in 1970's is based on an axiomatic foundation that has established its mathematical viability (Harker, 1998; Hauser \& Clausing, 1998). The diverse applications of the technique are due to its simplicity, and ability to cope with complex decision-making problems. The AHP methodology has been widely used for solving problems where definite quantitative measures are not available to support correct decisions. (Handfield, 1994) provided an extensive list of references on the AHP methodology and its applications. The AHP begins with representing a complex problem as a hierarchy in the following order:

1. At the top level of the hierarchy, the goal (objective) upon which the best decision should be made is placed.

2. The next level of the hierarchy contains attributes or criteria that contribute to the quality of the decisions. Each attribute may be decomposed into more detailed attributes.

3. The lowest level of the hierarchy contains decisionalternatives.

After the hierarchical network is constructed, one can determine the weights (importance measures) of the elements at each level of the decision hierarchy, and synthesize the weights to determine the weights of decision alternatives. First, a comparison matrix, which includes Level 1 elements (criteria) of the hierarchy, is constructed. Then, a ratio scale pairwise comparison of each pair of criteria with respect to the overall goal is performed. The relative importance of each criterion is estimated using an eigenvector approach (Lein, 2003) or other methods. Then, the relative importance of each alternative with respect to each criterion is determined using similar pairwise comparisons. The pairwise comparisons between the criteria as well as between the alternatives are made using the nine-point scale proposed by Arbel and Seidmann (1994).

Typically, a decision-maker provides the upper triangular of the comparison matrix, while reciprocals are placed in the lower triangular Arbel and Seidmann (1994). In other words, if scale factor 5 is assigned to entry $(i, j)$ of the matrix, where $i$ and $j$ is the row and column of the comparison matrix, respectively, then value $1 / 5$ is
Research article

CIndian Society for Education and Environment (iSee)
"Analytical hierarchy process" http://www.indjst.org
Venkatamuni et al. Indian J.Sci.Technol. 
assigned to the entry (j, i). Also, each criterion or alternative has equal importance. Therefore, the diagonal elements of the matrix always equal to one. The advantage of the pairwise comparison of elements instead of direct assignments of preference values is that the latter results in inaccuracies, since the comparison process is more complex. The consistency meaning in the team selection process is defined as follows. If a respondent moderately prefers team member B over C and team member $C$ over $D$, then it is expected that $s /$ he will prefer team member $B$ over $D$ as the highest possible order of affirmation. The consistency index (Cl) and consistency ratio $(\mathrm{CR})$ for comparison matrix $\mathrm{A}$ are computed as follows:

$\mathrm{Cl}=\left(\lambda_{\max }-n\right) /(n-1)$ Where $\lambda_{\max }$ is largest eigne value of Pairwise comparison matrix,

$\mathrm{CR}=\mathrm{Cl} / \mathrm{RI}$ where $\mathrm{RI}$ is average random consistency index number, which depends on the size of comparison matrix. In the team selection problem, the AHP is applied by Kusiak and Belhe (1992). The values that the team members contribute to the criteria, established by the customer vary. To select a team, one must elicit all possible characteristics or attributes desired, and then develop a method for assessing their importance to the overall goal (Wang \& Kusiak, 1993). Therefore, all the elements, i.e., customer requirements, engineering characteristics and team members are represented into various levels called as analytical Hierarchical structure shown in Fig. 1.

\section{Mathematical programming model}

The multi-functional team's formation problem is formulated as an integer-programming model (Maddux et al., 2001). The model is based on the engineering characteristics-team member type priority incidence matrix. Each row of the matrix corresponds to a distinct engineering characteristic of the product. Each column denotes a type of a team member. Each entry $w_{i j}$ in the incidence matrix indicates the weight (priority) of a member of functional team of type $\mathrm{j}$ with respect to engineering characteristic $\mathrm{i}$. To formulate the model the following notation is introduced:

$\mathrm{i}=$ index for engineering characteristics

$j=$ functional team type

$\mathrm{n}=$ number of engineering characteristics

$m$ - Number of types of functional teams

$\mathrm{w}_{\mathrm{ij}}$ - weight (priority) of a member of functional team of type $j$ with respect to engineering characteristic $i$ $t$ - Number of multifunctional teams, $m_{j}-$ number of

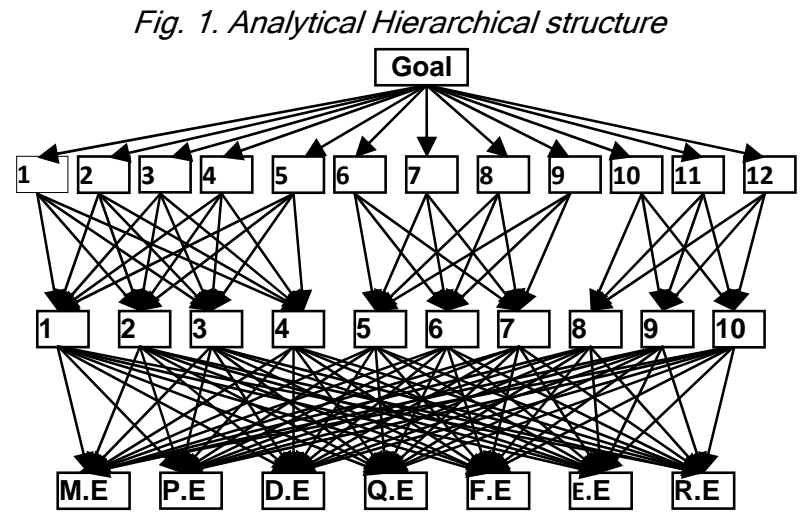
undertake.

Vol. 3 No. 5 (May 2010)

ISSN: 0974- 6846

characteristics that a member of functional team $\mathrm{j}$ can

The value of $m_{j}$ is a function of time, technological and scheduling constraints, and so on.

$M$ - an arbitrary large positive $n$ number

If $x_{i j}=1$, member of functional team of of type $j$ belongs to the multidisciplinary team that is responsible for engineering characteristic $i$. otherwise 0

The objective function of the model ((1) - (6)) maximizes the total of priority weights of the multi-functional teams.

$\operatorname{Max} \sum_{i=1}^{n} \sum_{j=1}^{m} w_{i j} x_{i j}$

Subject to

$$
\begin{aligned}
& \sum_{i=1}^{n} x_{i j} \leq m_{j} \\
& \sum_{i=1}^{n} y_{i} \leq t \text { to } \mathrm{m} \text { (No. of Projects) }
\end{aligned}
$$

$Y$ is name of the Team and assumed to be 10 teams $(t=1$ to 10)

$$
\begin{aligned}
& \sum_{i=1}^{n} x_{i j} \leq b_{j} \\
& \mathrm{j}=1 \text { to } \mathrm{m} \text { (Budget constraint) } \\
& \sum_{i=1}^{n} x_{i j} \leq T_{i j} \\
& \mathrm{j}=1 \text { to } \mathrm{m} \text { (Time Constraint) } \\
& \sum_{j=1}^{m} x_{i j} \leq M y_{i} \\
& \mathrm{i}=1,2 \ldots \mathrm{n} \text {, } \\
& \mathrm{x}_{\mathrm{ij}}=0 \\
& \mathrm{i}=1,2,3 \ldots . \mathrm{n}, \mathrm{j}=1,2,3 \ldots . . \mathrm{m} \\
& y_{i}=0,1, i=1,2,3, \ldots \ldots . . n-----(8)
\end{aligned}
$$

Constraint (2) imposes an upper bound on the number of projects that a team member of type $j$ is to undertake. Constraint (3) specifies the required number of teams. Constraint (4) mentions budget required for each team. Constraint (5) ensures Time required for each team. Constraint (6) ensures that the team member of type $\mathrm{j}$ belongs to the team i only when the team $i$ is formed. 
Constraints $(7 \& 8)$ make the results in integral form. Next, the AHP framework and mathematical programming formulation are illustrated with a case study.

Hypothetical model for team formation

Consider a company that is to form teams to develop a new model of a mobile phone. Construct a Hierarchical diagram with customer requirements, Engineering characteristics and team

Table1. Thomas satty scale ratings

\begin{tabular}{|c|l|}
\hline Rank & Verbal justification \\
\hline 9 & Extremely preferred \\
\hline 8 & Very strongly to extremely \\
\hline 7 & Very strongly preferred \\
\hline 6 & Strongly to very strongly \\
\hline 5 & Strongly preferred acv \\
\hline 4 & Moderately to strongly \\
\hline 3 & Moderately preferred \\
\hline 2 & Equally to moderately \\
\hline 1 & Equally preferred \\
\hline
\end{tabular}

members in various disciplines at different levels as shown in Fig.1. The highest level in the structure is the goal, i.e., design and development of mobile phone. The attributes, i.e., customer requirements and engineering characteristics, which are required to satisfy the goal, are placed on the Level 1 and 2 respectively. At the last level of the hierarchy, the decision alternatives (i.e., team members) are placed to gather information from the Customers (Paschalina, 2002) and matching with engineering characteristics as shown in Fig.

Table 2.Customer requirements - Engineering characteristics planning matrix

\begin{tabular}{|c|c|c|c|c|c|c|c|c|c|c|}
\hline & $\bar{U}$ & ঠָ & ญ् & ن & Uి & $\begin{array}{l}0 \\
\text { U }\end{array}$ & $\hat{U}$ & $\begin{array}{l}\infty \\
\text { U }\end{array}$ & 它 & 음 \\
\hline CR1 & $x$ & $x$ & $x$ & $x$ & & & & & & \\
\hline CR2 & $x$ & $x$ & $x$ & $x$ & & & & & & \\
\hline CR3 & $x$ & $x$ & $x$ & $x$ & & & & & & \\
\hline CR4 & $x$ & $x$ & $x$ & $x$ & & & & & & \\
\hline CR5 & $x$ & $x$ & $\mathrm{x}$ & $x$ & & & & & & \\
\hline CR6 & & & & & $x$ & $x$ & $x$ & & & \\
\hline CR7 & & & & & $x$ & $x$ & $x$ & & & \\
\hline CR8 & & & & & $x$ & $x$ & $x$ & & & \\
\hline CR9 & & & & & $x$ & $x$ & $x$ & & & \\
\hline CR10 & & & & & & & & $x$ & $x$ & $x$ \\
\hline CR11 & & & & & & & & $x$ & $x$ & $x$ \\
\hline CR12 & & & & & & & & $x$ & $x$ & $x$ \\
\hline
\end{tabular}

customer requirements are mentioned, and at the second level of hierarchy the engineering characteristics are prioritized with respect to the customer requirements. The engineering characteristics are decomposed as some of them are not pertinent to the customer requirements. For eg., the relationships between engineering characteristics $5,6,7,10$ are not connected to the $1,2,3,4$, and 5

customer requirements. The prioritization is done using comparison matrices describing the relative impact of the engineering characteristics to the customer requirements. Based on the weights of customer requirements, the normalized weights of engineering characteristics are derived as shown in Table 5.

Next, a matrix that includes the elements of the lowest level of hierarchy in Fig. 2 is constructed. The issue here is to determine which team member has more impact on an engineering characteristic 1. First, project managers, customers and suppliers develop a planning matrix in which the customer requirements are related to the engineering characteristics. The highest level in the structure is the goal, i.e., design and development of mobile phone. The attributes, i.e., customer requirements and engineering characteristics, which are required to satisfy the goal, are placed on the level 1 and 2, respectively. At the last level of the hierarchy, the decision alternatives (i.e., team members) are placed.

The next step is to prioritize customer requirements using pairwise comparisons and the relative importance scale in Table1.for calculating the weights.Identify engineering characteristics for customer requirements is shown in table 2 ..

The comparison matrix for the 12 customer requirements is shown in Table 3 . The resulting weights of the customer requirements are shown in Table 4. At the First level of the hierarchy the

Table 3. Customer requirements priority vectors

\begin{tabular}{|c|c|c|c|}
\hline $\begin{array}{c}\text { Customer } \\
\text { requirements }\end{array}$ & $\begin{array}{l}\text { Priority } \\
\text { vector }\end{array}$ & \multicolumn{2}{|c|}{$\begin{array}{c}\text { Table 4. Normalized } \\
\text { weights of engineering } \\
\text { characteristics }\end{array}$} \\
\hline C.R 1 & 0.06872 & Engineering & Priority \\
\hline C.R 2 & 0.02786 & ristic & weights \\
\hline C.R 3 & 0.09308 & EC-1 & 0.11326 \\
\hline C.R 4 & 0.04295 & EC-2 & 0.08344 \\
\hline C.R 5 & 0.03192 & EC-3 & 0.04348 \\
\hline C.R 6 & 0.14652 & EC-4 & 0.02435 \\
\hline C.R 7 & 0.04083 & EC-5 & 0.13482 \\
\hline C.R 8 & 0.02645 & EC-6 & 0.14659 \\
\hline C.R 9 & 0.09079 & EC-7 & 0.02319 \\
\hline C.R 10 & 0.04356 & EC-8 & 0.28152 \\
\hline C.R 11 & 0.31326 & EC-9 & 0.11671 \\
\hline C.R 12 & 0.07406 & EC-10 & 0.03264 \\
\hline
\end{tabular}

"Analytical hierarchy process" http://www.indjst.org considered. For eg., in the comparison matrix for the first team member the importance of team members in building the screen resolution system is evaluated. Therefore, ten comparison matrices A1, A2, A10 are constructed, one for each engineering characteristic at Level 2. The pair wise comparison of team members with respect to each engineering characteristic in level 2 is important, as the members receive different ratings when using different criteria. Following a prioritization scheme similar to the one described above, one derives weights for each team with respect to each engineering characteristic at level 2. The resulting priority vectors from ten matrices are weighted (multiplied) by the importance $w_{i}$ of engineering characteristic $\mathrm{i}, \mathrm{i}=1, \ldots, 10$, derived in Table 4. Then, the aggregate priority matrix is constructed which lists the priority measures for each team member with respect to each engineering characteristic of the mobile phone is normalized with respect to the overall goal. These priority vectors $W_{1}, W_{2}, W_{3}, W_{4}, W_{5}, W_{6}$, and $W_{7}$ are summarized in Table Indian J.Sci.Technol. 
Indian Journal of Science and Technology

6 and the normalized weights of the team members with respect to each engineering characteristic are summarized in Fig.3.It can be assumed that at most 10 teams are to be formed. Table 5 shows the number of characteristics that each team member type able to undertake.

The composite weights and number of characteristics from the Table 5 and Table 6 respectively are used as coefficients for the object function and constraints. The integer programming problem is solved by TORA optimization software and the optimal results at 375 iteration are presented in results section.

\section{Results and team structure}

Team-I \{ME, P.E, D.E, Q.E, F.E, E.E, R.E\}

Team-II \{ME, P.E, D.E, Q.E, F.E, E.E, R.E\}

Team-III \{ME, P.E, D.E, R.E\}

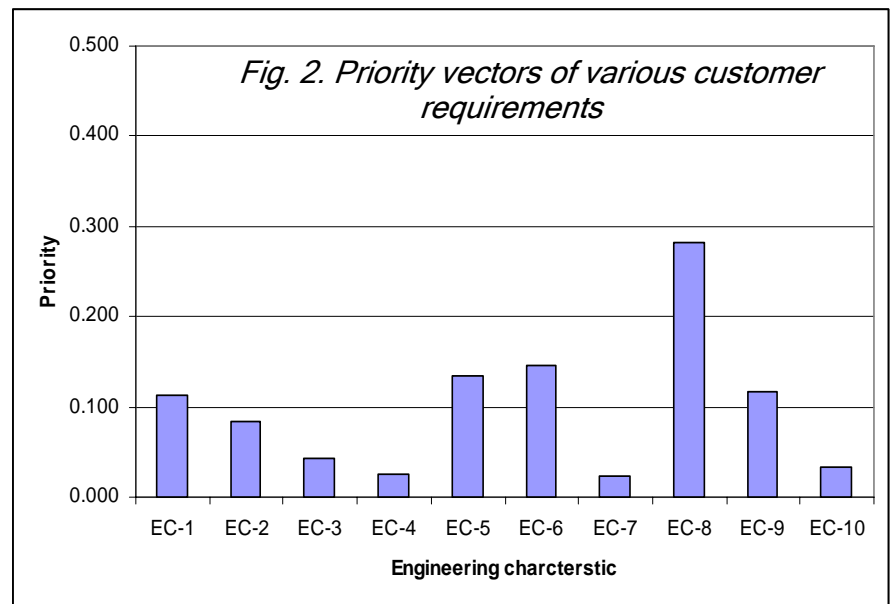

Team-IV \{ME, D.E, R.E $\}$

Team-V \{ME, P.E, D.E, Q.E, F.E, E.E, R.E $\}$

Team-VI $\{$ ME, P.E, F.E, E.E, R.E\}

Team-VII \{D.E\}

Team-VIII \{ME, D.E, Q.E, F.E, E.E, R.E\}

Team-IX \{ME, P.E, D.E, Q.E, F.E, E.E, R.E $\}$

Team-X $\{\mathrm{ME}\}$

\section{Discussion and conclusion}

This paper explain the method to form a cross functional teams from existing professional bodies by considering customers' requirement. This provides option to frame the hierarchy with customer requirements, engineering characteristics and people who are involved in product design and development. Information on customers is collected from retailer and it identifies approximate engineering characteristics. All the above

Table 5. Number of Characteristics allotted to each group of engineers

\begin{tabular}{|c|c|c|c|c|c|c|c|}
\hline & ME & P.E & D.E & Q.E & F.E & E.E & R.E \\
\hline No. of Projects & 9 & 6 & 9 & 5 & 5 & 6 & 7 \\
\hline
\end{tabular}

"Analytical hierarchy process" http://www.indjst.org
Research article

CIndian Society for Education and Environment (iSee)
Vol. 3 No. 5 (May 2010)

ISSN: 0974- 6846

Table 6. summarized composite weights of engineering characteristics w.r.t team members

\begin{tabular}{|l|l|l|l|l|l|l|l|}
\hline & T-I & T-II & T-III & T-IV & T-V & T-VI & T-VII \\
\hline EC-1 & 0.0171 & 0.0248 & 0.0182 & 0.0213 & 0.0253 & 0.0232 & 0.0230 \\
\hline EC-2 & 0.0030 & 0.0116 & 0.0149 & 0.0144 & 0.0151 & 0.0111 & 0.0179 \\
\hline EC-3 & 0.0050 & 0.0049 & 0.0061 & 0.0048 & 0.0042 & 0.0043 & 0.0057 \\
\hline EC-4 & 0.0017 & 0.0034 & 0.0028 & 0.0031 & 0.0027 & 0.0029 & 0.0027 \\
\hline EC-5 & 0.0066 & 0.0147 & 0.0085 & 0.0149 & 0.0082 & 0.0147 & 0.0078 \\
\hline EC-6 & 0.0348 & 0.0073 & 0.0055 & 0.0059 & 0.0063 & 0.0053 & 0.0060 \\
\hline EC-7 & 0.0016 & 0.0020 & 0.0026 & 0.0023 & 0.0024 & 0.0022 & 0.0013 \\
\hline EC-8 & 0.0121 & 0.0042 & 0.0074 & 0.0070 & 0.0078 & 0.0065 & 0.0072 \\
\hline EC-9 & 0.0191 & 0.0095 & 0.0125 & 0.0102 & 0.0128 & 0.0098 & 0.0130 \\
\hline EC-10 & 0.0022 & 0.0018 & 0.0020 & 0.0014 & 0.0015 & 0.0013 & 0.0016 \\
\hline
\end{tabular}

information is structured as hierarchy. Majority of time is spent on the preparation of pair wise comparison matrix and check its consistency, that leads to wastage of time which can be minimized using prepared excel work book. With this we can reduce $90 \%$ of calculation time. Frame

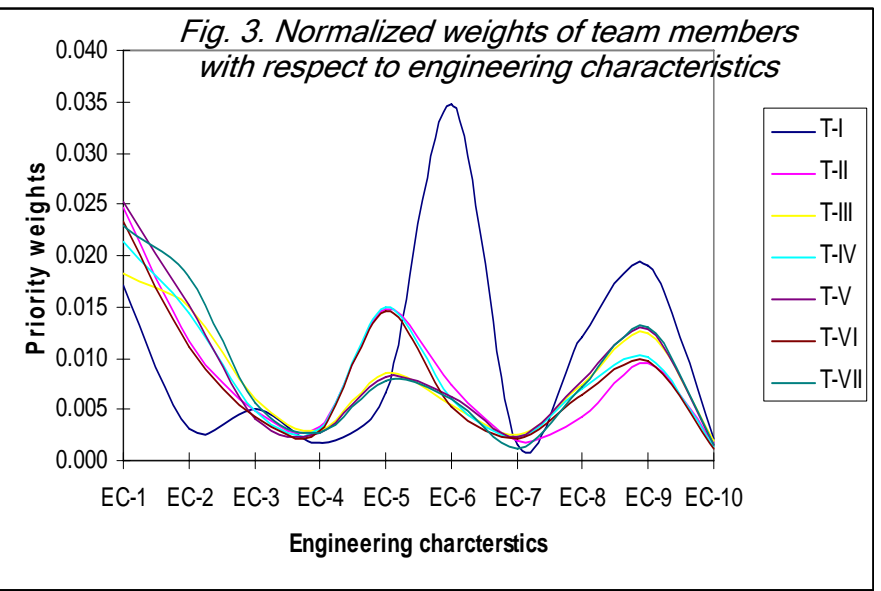

the mathematical model to calculate number of teams required for the selected products. The number of teams depending on the number of projects, time, and budget treated as constraints as well as goals in the model. The objective function is number of team members in each team with different specializations. Solve the problem using TORA optimization software. Team formation is one of the ideal approaches to minimize and planning the human resource requirement in product design. We used AHP for prioritizing team members based on the customer requirements and engineering characteristics of the product. This method permits a great amount of flexibility in the formation of teams, i.e., one can add an additional factor to the team selection hierarchy and perform the analysis without reorganization the entire model. Similarly, the factors can be removed when necessary. The approach presented here is perhaps the first attempt to formalize the team selection process. This approach can mention exact requirement of staff members for the manufacturing, we can achieve easily lean principles by avoiding excess
Venkatamuni et al. Indian J.Sci.Technol. 
man power in manufacturing and product design and development. Thus team formation is the key role in minimizing the time, recourses and so on, in consequence of for achieving lean product development.

\section{References}

1. Aczel J and Saaty TL (1983) Procedures for synthesizing ratio judgments. J. Math.Psychol. 27, 93102.

2. Arbel A and Seidmann A (1994) Performance evaluation of flexible manufacturing systems. IEEE Trans. Sys. Man. Cybernetics. 14, 606-617.

3. Mullens MA, Armacost RL, Componation P (1994) An AHP framework for prioritizing customer requirements in QFD: An industrial housing application. IIE Trans. 26, 72-79.

4. Askin RG and Sodhi M (1994) Organization of teams in concurrent engineering. In: Handbook of design, manufacturing and automation. Dorf RD \& Kusiak A (Eds.), John Wiley \& Sons Inc., NY. pp: 85-105.

5. Lida $\mathrm{Xu}$, Zongbin Li Shancang Li fengming Tang (2007) A decision support system for product design in concurrent engineering Decission support systems. 42 , 2029-2042.

6. Harker DT (1998) Theory of ratio scale estimation: Saaty's analytical Hierarchy process. Management Sci. 36, 269-273.

7. Hauser JR and Clausing D (1998) The house of quality. Harvard Business Rev. May-June, 63-73.

8. Handfield RB (1994) Effects of concurrent engineering on make-to-order products. IEEE Trans. Engg. Management. 41(4), 384-394.

9. Lein $M(2003)$ Capturing design rationale in concurrent engineering teams. Computer. 3, 39-47.

10. Kusiak $A$ and Belhe $U$ (1992) Concurrent engineering: A design process perspective. Proc. Amer. Soc. Mech. Engr. 59, 387- 401.

11.Wang $\mathrm{J}$ and Kusiak A (1993) Decomposition in concurrent design. In: Concurrent engineering: Automation, tools, and techniques. Kusiak A (Ed.), John Wiley \& Sons, Inc., NY. pp: 481- 507.

12. Maddux GA, Amos RW and Wyskida AR (2001) Organization can apply quality function deployment as strategic planning tool. Industrial Engg. 23(9), 33-37.

13.Paschalina (Lilia) Ziamou (2002) Commercializing new technologies: consumers' response to a new interface. J. Product Innovation Management. 19, 365-374. 